\title{
MITIGATION OF WELDING FUME WITH VITAMIN C
}

\author{
B.S. OKEDIRAN ${ }^{1 *}$, S.A. AMID ${ }^{2}$, K.Y. SULEIMAN ${ }^{1}$, O.A. MAKINDE ${ }^{3}$, \\ B.A. ALABA ${ }^{4}$ and E. Olajide ${ }^{4}$ \\ ${ }^{1}$ Department of Veterinary Physiology and Biochemistry, Faculty of Veterinary Medicine, University of Ilorin, \\ Ilorin, Nigeria \\ ${ }^{2}$ Department of Veterinary Surgery and Radiology, Faculty of Veterinary Medicine, University of Ilorin, Ilorin, \\ Nigeria. \\ ${ }^{3}$ Department of Veterinary Surgery and Theriogenology, Federal University of Agriculture, Abeokuta, Nigeria \\ ${ }^{4}$ Department of Veterinary Medicine, University of Ibadan, Nigeria.
}

Received: 24 March 2021; Accepted: 10 April 2021

\begin{abstract}
Welding fumes are composed of fine and ultrafine particles, which when it gained access to the body system either via inhalation or as food or water contaminants can elicit various haematological and biochemical changes. In order to determine the haematological changes elicited by welding fumes and it's mitigation by ascorbic acid, a total of fifteen male Wistar rats were randomly divided into three groups (A, B and C) of five animals per group. Group A served as the control while group $\mathrm{B}$ were kept in enclosed welding environment for adequate inhalation of the welding fume. Group $\mathrm{C}$ were equally kept in the enclosed welding environment but were daily orally administered $100 \mathrm{mg}$ of ascorbic acid for two weeks. At the end of two weeks of exposure, blood samples were obtained for haematological analyses. It was observed that exposure to the welding fumes predisposes the rats to macrocytic hypochromic anaemia and stress with evidence of neutrophilia and lymphopenia. These observed haematological perturbations were reversed by ascorbic acid back similar to that of the control group. It can be concluded that haematological perturbation induced by welding fume can be mitigated effectively by ascorbic acid without any deleterious effects.
\end{abstract}

Key words: fume, haematology, ascorbic acid,

\section{INTRODUCTION}

Welding is a noble occupation from ages. It involves joining metal parts by heating the pieces to melting temperatures. Tungsten inert welding gas is of interest to welders because of its ability to generate high strong metallic welding and produces quality welds (Lehnert et al., 2012). During welding process, fume is generated that is

Corresponding author: B.S. Okediran

E-mail address: okediranbabatunde@gmail.com

Present address: Department of Veterinary Physiology and Biochemistry, Faculty of Veterinary Medicine, University of Ilorin, Ilorin, Nigeria composed of metallic particles. These metallic particles in the fume include manganese $(\mathrm{Mn})$, beryllium (Be), cadmium $(\mathrm{Cd})$, chromium $(\mathrm{Cr})$, cobalt (Co), copper $(\mathrm{Cu})$, iron $(\mathrm{Fe})$, lead $(\mathrm{Pb})$, mercury $(\mathrm{Hg})$, molybdenum (Mo), nickel (Ni), zinc (Zn), antimony ( $\mathrm{Sb}$ ), and vanadium (V) (OSHA, 1995). Welders are exposed to a wide range of metals and non-metals with varying and sometimes additive toxic effects. In addition, they are commonly exposed to physical hazards including heat, electrical current, noise, vibration, visible, infrared and ultraviolet radiation (Benjamin, 1997). Inhalation of these particulate materials 
could trigger release of several inflammatory cytokines to ward off these pollutants generated from welding fume (Firas and Qasim, 2013). Some metals ions, such as cadmium, lead, arsenic and mercury, are non-essential xenobiotics and are injurious to health (Sani and Abdullahi, 2019). Other metals ions, such as chromium, copper, manganese, molybdenum, selenium and zinc, are essential for good health but could be harmful above certain levels (Ranjana and Peyush, 2011).

Vitamins are defined as small organic molecules present in diet which are required in small amounts. Most of the vitamins are not synthesized in the body and hence they must be supplied in the diet. Vitamin $\mathrm{C}$ or ascorbic acid is a water soluble vitamin with antioxidant and chelating properties (Meister, 1992). Ascorbic acid has been reported to chelate heavy metals and increases its urinary excretion from the body, also it reverses anaemia caused by heavy metals toxicity (Okediran et al., 2009). Epidemiological studies have shown that exposure to welding fumes is associated with metal fume fever with alteration of haematological and biochemical parameters. The aim of this study is to unravel the haematological changes due to exposure to welding fume and its mitigation by ascorbic acid supplementation in male Wistar rats.

\section{MATERIALS AND METHODS}

\section{Experimental Animals}

A total of fifteen male Wistar rats were used for this investigation. The average weight of the rats was $152 \pm 3.50 \mathrm{~g}$. They were provided with water and laboratory animal feed (Fat/oil 6\%, crude fibre 5\%, calcium $1 \%$, available phosphorus $0.4 \%$, lysine $0.85 \%$, methionine $0.35 \%$, salt $0.3 \%$, crude protein $18 \%$, metabolisable energy 2900Kcal.kg-1, manufactured by TOPFEEDS $₫$, (Lagos, Nigeria). Experimental animals were acclimatized to the room temperature $\left(20.0 \quad{ }^{\circ} \mathrm{C}\right)$ and pressure $(760 \mathrm{mmHg})$ before the start of the experiment.

\section{Animal Ethics \\ All experimental protocols carried out on the animals were in accordance with the international accepted principles for laboratory animal use and were approved by the Ethics Committee (UIL/FVERC/011/2020) on Laboratory animal use of the Faculty of Veterinary Medicine, University of Ilorin, Nigeria.}

\section{Exposure to the fume}

A total of fifteen male Wistar rats were used for the experiment. They were randomly divided into three groups (A-C) of five animals per group.

Group A: the rats served as the control, are non-exposed to the welding fume in a wellventilated animal house.

Group B: the rats were kept at welding site (containing welding machines with Hyundai Welding electrodes low hydrogen E $70183.2 \mathrm{~mm}$ made in U.S.A) enclosure for maximum exposure to the fume only for two weeks.

Group C: the rats were administered $100 \mathrm{mg}$ of vitamin $\mathrm{C}$ daily as a supplement and exposed to the welding fume at the welding site.

\section{Collection of blood samples}

At the end of two weeks of fume exposure, blood samples were collected via the occular median canthus of all experimental rats into EDTA tubes. Packed cell volume, red blood cell and white blood cell counts were determined as described by Schalm et al. (1975).

\section{Statistical analysis}

Results were expressed as mean \pm SEM. Analysis of the data was done using oneway analysis of variance followed by the Duncan multiple range post hoc test. $\mathrm{P}$ value $<0.05$ were considered significant. 
All analyses were done using Statistical Package for Social Sciences version 16.

\section{RESULTS}

Table 1 shows the packed cell volume (PCV), red blood cell counts (RBC) and white blood cell counts (WBC) of male Wistar rats exposed to welding fume alone (group B) as well as welding fume and vitamin $\mathrm{C}$ (group C) for a period of two weeks. There was a significant decrease $(\mathrm{P}<0.05)$ in the packed cell volume and red blood cells count of rats exposed to the welding fume alone compared to the control group, however there was no significant change $(\mathrm{P}<0.05)$ in the packed cell volume and the red blood cell count of rats exposed to the fume and administered vitamin $\mathrm{C}$, compared to the control group. The white blood cell count showed significant increase in group exposed to welding fume alone compared to the control, however there was no significant change $(\mathrm{P}<0.05)$ in the control group compared to the group exposed to the fume and administered vitamin $\mathrm{C}$.

Table 1: The packed cell volume (PCV), red blood cell counts (RBC) and white blood cell counts (WBC) of male Wistar rats exposed to welding fume alone (group B) as well as welding fume and vitamin $\mathrm{C}$ (group C) for a period of two weeks.

\begin{tabular}{llll}
\hline Parameters & PCV $(\%)$ & RBC Count $\left(\mathbf{1 0}^{\mathbf{1 2}} / \mathbf{L}\right)$ & WBC Count $\left(\mathbf{1 0}^{\mathbf{9}} / \mathbf{L}\right)$ \\
\hline Group A (control) & $43.00 \pm 2.22 \mathrm{a}$ & $5.94 \pm 0.23 \mathrm{a}$ & $10.30 \pm 0.26 \mathrm{a}$ \\
Group B & $32.21 \pm 1.02 \mathrm{~b}$ & $3.12 \pm 1.21 \mathrm{~b}$ & $15.39 \pm 1.23 \mathrm{~b}$ \\
Group C & $40.30 \pm 2.11 \mathrm{a}$ & $4.88 \pm 1.01 \mathrm{a}$ & $9.02 \pm 0.24 \mathrm{a}$ \\
\hline
\end{tabular}

Values within the same column with different superscripts (a,b) are significantly different at $p<0.05$

Table 2 shows the haemoglobin concentration $(\mathrm{Hb})$, mean corpuscular volume (MCV) and mean corpuscular haemoglobin concentration (MCHC) of male Wistar rats exposed to welding fume (group B) as well as welding fume and vitamin $\mathrm{C}$ (group $\mathrm{C}$ ) for a period of two weeks. There was a significant decrease in the haemoglobin concentration and an increase in the mean corpuscular volume of rats exposed to the fume alone compared to the control group, however there was no significant change in the mean corpuscular haemoglobin concentration. There were no significant change in the haemoglobin concentration, mean corpuscular volume and mean corpuscular haemoglobin concentration of rats exposed to fume and vitamin $\mathrm{C}$ compared to the control group.

Table 2: The haemoglobin concentration, mean corpuscular volume (MCV) and mean corpuscular haemoglobin concentration (MCHC) of male Wistar rats exposed to welding fume for a period of two weeks.

\begin{tabular}{llll}
\hline Parameters & Hb $(\mathbf{g} / \mathbf{d l})$ & MCV $(\mathbf{f L})$ & MCHC (g/d) \\
& & & \\
\hline Group A (control) & $15.71 \pm 1.43 \mathrm{a}$ & $67.70 \pm 1.72 \mathrm{a}$ & $33.80 \pm 1.05 \mathrm{a}$ \\
Group B & $12.23 \pm 1.72 \mathrm{~b}$ & $89.65 \pm 1.61 \mathrm{~b}$ & $30.12 \pm 1.96 \mathrm{a}$ \\
Group C & $14.53 \pm 1.53 \mathrm{a}$ & $66.61 \pm 1.34 \mathrm{a}$ & $32.11 \pm 1.65 \mathrm{a}$ \\
\hline
\end{tabular}

Values within the same column with different superscripts $(a, b)$ are significantly different at $p<0.05$

Table 3 shows the white blood cells differentials of male Wistar rats exposed to welding fume (group B) as well as welding fume and vitamin C (group C) for a period of two weeks. There was a significant neutrophilia in group B exposed to welding fumes only compared to the control group. However, in group $\mathrm{C}$ exposed to fumes and 
vitamin $\mathrm{C}$ experienced no significant change compared to the control but a significant neutropenia compared to group $\mathrm{B}$ exposed to the welding fumes. There was a mild lymphophenia in group B exposed to welding fumes compared to the control, however lymphocytosis was observed in group $\mathrm{C}$ exposed to welding fumes and vitamin $\mathrm{C}$ as compared to the control group.

Table 3: The white blood cells differential of male Wistar rats exposed to welding fume as well welding fume and vitamin $\mathrm{C}$ for a period of two weeks.

\begin{tabular}{llllll}
\hline Parameters & $\begin{array}{l}\text { Neutrophil } \\
(\boldsymbol{\%})\end{array}$ & $\begin{array}{l}\text { Eosinophil } \\
(\boldsymbol{\%})\end{array}$ & $\begin{array}{l}\text { Basophil } \\
(\boldsymbol{\%})\end{array}$ & $\begin{array}{l}\text { Monocyte } \\
(\boldsymbol{\%})\end{array}$ & $\begin{array}{l}\text { Lymphocyte } \\
(\boldsymbol{\%})\end{array}$ \\
\hline $\begin{array}{l}\text { Group A } \\
\text { (control) }\end{array}$ & $52.67 \pm 2.18 \mathrm{a}$ & $1.33 \pm 0.33 \mathrm{a}$ & $1.00 \pm 0.18 \mathrm{a}$ & $1.00 \pm 0.48 \mathrm{a}$ & $30.00 \pm 3.06 \mathrm{a}$ \\
Group B & $67.06 \pm 2.01 \mathrm{~b}$ & $2.00 \pm 0.01 \mathrm{a}$ & $1.05 \pm 0.11 \mathrm{a}$ & $1.20 \pm 0.31 \mathrm{a}$ & $27.55 \pm 2.15 \mathrm{~b}$ \\
Group C & $50.23 \pm 2.00 \mathrm{a}$ & $2.12 \pm 0.11 \mathrm{a}$ & $1.12 \pm 0.13 \mathrm{a}$ & $1.11 \pm 0.22 \mathrm{a}$ & $35.29 \pm 2.99 \mathrm{a}$ \\
\hline
\end{tabular}

Values within the same column with different superscripts $(a, b)$ are significantly different at $\mathrm{p}<0.05$

\section{DISCUSSION}

Welding activities is a common source of environmental hazards due to fumes that are generated. The fumes composed of particulate metals such as lead, chromium, mercury, etc that gained entrance into the body system either via inhalation or intradermally or as a contaminant in the food or water. Once in the body they are transported via the blood stream to various parts of the body where they are deposited resulting in various pathology (Sanni and Abdulahi, 2019).

Blood or blood constituents are the best indicators of the present internal exposure to fumes or toxicants because it is the major transport system. The blood composed of the cellular portion and the liquid part, the plasma. Both the cellular portion and the plasma interact with fumes to produce the haematological changes noticed in this study.

The results in tables 1 and 2 shows that exposure of rats to welding fumes predisposes them to macrocytic and mild hypochromic anaemia. This anaemia is probably due to the fumes constituents of heavy metals such as lead or mercury destroying the circulating red cells. The red cells has a strong binding affinity for these heavy metals thereby increasing osmotic fragility of the cell. The increased osmotic fragility of the red cells causes lysis of these cells as a result of oxidative damage induced on the cell membrane by these heavy metals (Moli et al., 2017; Ibeh et al., 2016; Bai et al., 1980).

Exposure of male rats to fumes resulted in leucocytosis with marked neutrophilia and mild lymphopenia. Neutrophils are the line of defence against the fumes and its constituents. It is an indication of the inflammatory response during the stress experienced by the rats. Peripheral blood neutrophilia has also been found to increase, following short-term inhalation exposure to other substances, such as ozone and compost dust and fumes generated in the environment (Muller et al., 2006). In accordance with current results, Kim et al. (2005), reported that welding fume exposure was associated with a significant increase in white blood cell and neutrophil counts.

Vitamin $\mathrm{C}$ or ascorbic acid is a water soluble vitamin with antioxidant and chelating potentials. It was observed in this study that ascorbic acid was able to reverse the haematological changes noticed in rats exposed to welding fumes. 
It was observed that the anaemia was reversed in the group administered vitamin $\mathrm{C}$ along with the fumes. The packed cell volume, red cell count, haemoglobin concentration and mean corpuscular volume in group $\mathrm{C}$ were reversed back to be similar to that of the control parameters. The leukocytosis, neutrophilia and lymphopenia observed in group B were also reversed due to administration of vitamin $C$. It could be that the anaemia was reversed because vitamin $\mathrm{C}$ was able to chelate these fumes constituent of heavy metals and were excreted out of the body (Okediran et al., 2016) Also, due to its antioxidant potential it was able to quench free radicals generated by the fume constituents thereby enhancing the stability of the erythrocytes membrane.

These findings are in agreement with other workers who reported the protective effects of ascorbic acid in metal-induced toxicity (Chattopadhyay et al., 2001; Patra et al., 2001; Tandon et al., 2001). It was equally reported that orally administered ascorbic acid was able to chelate and decrease the toxic effects of environmental heavy metal toxicants (Dalley et al., 1990). Other antioxidants like lipoic acid (Pande and Flora, 2002), vitamin E (Flora et al., 2003; Patra et al., 2001) and $\mathrm{N}$-acetylcysteine (Pande et al., 2001) have been shown to protect against fumes with heavy metals.

It can be concluded from the study that exposure of rats to welding fumes resulted in haematological changes which are reversed by administration of ascorbic acid.

\section{REFERENCES}

Bai, K.M.; Krishnakumari, M.K.; Ramesh, H.P.; Shivanandappa, T. and Majumder, S.K. (1980): Short-term toxicity study of zinc phosphide in Albino rats (Rattus norvegicus). Indian Journal of Experimental Biology. 18(8): 854-857.
Behrman, A.J. (1997): Welders: In Occupational, Industrial, and Environmental Toxicology. Greenberg Mosby-Year Book, St Louis-Missouri. Pp 303-309.

Chattopadhyay, S.; Ghosh, S.; Debnath, J. and Ghosh, D. (2001): Protection of sodium arsenite induced ovarian toxicity by coadministration of Lascorbate (Vitamin C) in mature Wistar strain rats. Archive of Environmental Contaminant Toxicology 41:83-89.

Dalley, J.W.; Gupta, P.K. and Hung, C.T. (1990): A physiological pharmacokinetic model describing describing the disposition of lead in the absence and presence of Lascorbic acid in rats. Toxicological Letters 50: 337-348.

Firas, K.H. and Qasim, A.A. (2013): Effects of welding fume particles on heamatological parameters in male Albino rats. Zanco Journal of Medical Science 17 (2): 18-27

Flora, S.J.S.; Pande, M. and Mehta, A. (2003): Beneficial effect of combined administration of some naturally occurring antioxidants (vitamins) and thiol chelators in the treatment of chronic lead intoxication. Chemical Biological Interaction 145: 267-280.

Ibeh, N.; Aneke, J.; Okocha, C. and Obeagu, E. (2016): Occupational exposure to welders' flame could predispose to macrocytic anaemia in welders in Nwewi, South East Nigeria. Journal of Environmental and Occupational Sciences 5: 66-70.

Kim, J.Y.; Chen, J.C.; Boyce, P.D. and Christiani, D.C. (2005): Exposure to welding fumes is associated with acute systemic inflammatory responses. Occupational and Environmental Medicine 62:157-163. Lehnert, M.; Pesch, B. and Lotz, A. (2012): Exposure to inhalable, respirable, and ultrafine particles in welding fume. Annal of Occupational Hygiene.56 (5):557-567. 
Meister, A. (1992): Commentary on the antioxidant effects of ascorbic acid and glutathione. Biochemistry and Pharmacology 4(10): 1905-1915.

Moli, M.A.; Dabil, S.B.; Hasan, M. and Khan, M.H. (2017): Oxidative stress and DNA damage of welders. Journal of Sylhet Agril University 4(1):149159.

Muller, T.; Jorres, R.A.; Scharrer, E.M.; Hessel, H.; Nowak, D. and Radon, K. (2006): Acute blood neutrophilia induced by short-term compost dust exposure in previously unexposed healthy individuals. International Archive of Occupational and Environmental Health 79: 477-482.

Okediran, B.S.; Abam, E.; Ademuyiwa, O.; Odukoya, O.O. and Adamson, I. (2009): Membrane, Intracellular, Plasma and Urinary Sodium and Potassium in Occupational Lead Exposure: Effects of Vitamin $\mathrm{C}$ Supplementation. Trace Elements and Electrolytes 26: 49-59

Okediran, B.S.; Kasali, O.B.; Omotainse, S.O. and Akinloye, O.A. (2016): Haemato-Biochemical Alterations as Biomarkers of Lead Induced toxicity in male wistar rats. Bangladesh journal of veterinary medicine. 14 (2): 227-232.

OSHA. (1995): Welding Fumes (Total Particulate). Chemical Sampling Information. http:// www.oshaslc.gov/dts/chemicalsampling/data/C $\underline{\text { H276100.html }}$
Pande, M. and Flora, S.J.S (2002): Lead Exposure and Oxidative Stress: A Systematic Review Reviews of Environmental Contamination and Toxicology 236:193-238.

Pande, M.; Daniel, A. and Rossignol, D.A. (2001): The Use of N-Acetylcysteine as a Chelator for Metal Toxicity. The Therapeutic Use of NAcetylcysteine (NAC) in Medicine 34:169-179

Patra, R.C.; Swarup, D. and Dwidedi, S.R. (2001): Antioxidant effect of alpha tocopherol, ascorbic acid and Lmethionine on lead induced oxidative stress to the liver, kidney, and brain in rats. Toxicology 162: 81-88.

Ranjana, S. and Peyush, P. (2011): Effect of heavy metal on biochemical and haematological parameters in Cyprinus carpio and its use as a bioindicators of pollution stress. Journal of. Ecophysiological and Occupational Health 11: 21-28.

Sani, A. and Abdullahi, I.L. (2019): Effects of welding fumes on haematological parameters of male albino rats (Rattus norvegicus). Biochemistry and Biophysics Reports 19, 100651

Schalm, D.W.; Jain, N.C. and Carrot, E.J. (1975): Veterinary haematology 3rd edn Lea and Febiger, Philadelphia. Pp 20-27.

Tandon, S.K.; Chatterjee, M.; Bhargava, A.; Shukla, V. and Bihari, V. (2001). Lead poisoning in Indian silver refiners. Science Total Environment 281: 177-182. 